\title{
Article \\ Duplex Aging and Gas Nitriding Process as a Method of Surface Modification of Titanium Alloys for Aircraft Applications
}

\author{
Oleksandr Tisov ${ }^{1, *(\mathbb{D})}$, Magdalena Łępicka ${ }^{2}(0)$, Yurii Tsybrii ${ }^{2}$, Alina Yurchuk ${ }^{3}$, Myroslav Kindrachuk ${ }^{3}(\mathbb{D}$ \\ and Oleksandr Dukhota ${ }^{3}$ \\ 1 School of Aerospace Engineering, Xi'an Jiaotong University, Xi'an 710049, China \\ 2 Faculty of Mechanical Engineering, Bialystok University of Technology, 15-351 Bialystok, Poland; \\ m.lepicka@pb.edu.pl (M.Ł.); y.tsybrii@pb.edu.pl (Y.T.) \\ 3 Aerospace Faculty, National Aviation University, 03058 Kyiv, Ukraine; alina.yurchuk@npp.nau.edu.ua (A.Y.); \\ myroslav.kindrachuk@npp.nau.edu.ua (M.K.); oleksandr.dukhota@npp.nau.edu.ua (O.D.) \\ * Correspondence: oleksandrtisov@xjtu.edu.cn; Tel.: +86-156-190-775-73
}

check for

updates

Citation: Tisov, O.; Łępicka, M.;

Tsybrii, Y.; Yurchuk, A.; Kindrachuk, M.; Dukhota, O. Duplex Aging and Gas Nitriding Process as a Method of Surface Modification of Titanium Alloys for Aircraft Applications. Metals 2022, 12, 100. https:// doi.org/10.3390/met12010100 Academic Editors: Francesca Borgioli and Ilya Okulov

Received: 11 September 2021 Accepted: 20 December 2021 Published: 5 January 2022

Publisher's Note: MDPI stays neutral with regard to jurisdictional claims in published maps and institutional affiliations.

Copyright: (C) 2022 by the authors. Licensee MDPI, Basel, Switzerland. This article is an open access article distributed under the terms and conditions of the Creative Commons Attribution (CC BY) license (https:// creativecommons.org/licenses/by/ $4.0 /)$.

\begin{abstract}
This study discusses the effect of a duplex aging + nitriding process on the wear resistance of an aged double-phase titanium alloy, BT22. Nitriding was applied simultaneously with the heat treatment of the alloy, which is advantageous over the conventional heat and surface treatment methods applied to titanium alloys. According to the results, the thickness of the case depth of the nitrided samples was 40-50 $\mu \mathrm{m}$. Moreover, nitrogen was uniformly dispersed in the substrate, which was indicated by the hardness tests. The average microhardness of the substrate material was $300 \mathrm{HV}_{0.01}$, while the hardness of the top layer was $1190 \mathrm{HV}_{0.01}$, which is an almost four-fold increase. The applied duplex treatment substantially affected the wear performance of the tested alloy. For the untreated alloy, the maximum coefficient of friction was 0.8 , while in the surface-modified sample, the maximum fluctuations reached 0.6. The abrasive wear process was dominant in the nitrided samples, while delamination and adhesive wear were observed for the untreated specimens. The nitrided alloy exhibited double the wear resistance of the untreated samples. The proposed treatment does not require additional time or energy consumption, providing a substantial technological advantage over conventional methods. Though the alpha case reduces the mechanical performance of titanium, the nitriding of only the component sections intended to withstand friction will have a positive effect.
\end{abstract}

Keywords: duplex heat treatment; nitriding; BT22; titanium alloys; wear resistance

\section{Introduction}

Aerospace is an important field requiring advanced structural materials and engineering solutions, including composite materials (metal-fiber laminates, carbon-carbon and other advanced composites), high-strength heat-treatable aluminum alloys $(7075,7068$, 6061), CRES and PH steels (Type 316, 15-5PH, 17-7PH), nickel and cobalt superalloys (HAYNESS 188, Inconel 718, TMS 162), titanium alloys (Ti-64, BT22, Ti-1023), etc. Among metals, the application of titanium alloys is expanding due to their high corrosion resistance and excellent strength-to-weight ratio. However, if not specially treated, they are characterized by relatively low wear resistance [1,2], a significant limiting factor for their application. In virtually fixed joints (e.g., skin rivets, splined joints, threaded joints), vibration-induced displacements cause fretting wear. [3]. In kinematic joints (e.g., cylinder-compression rings, flap track-rollers), high-contact pressure limits the application of conventional anti-wear coatings [4]. One possible exception is fan blades, where thick, hard facing coatings protect the blades' root section and mid-span shrouds [5].

Although adhesion is vital for any coating, diffusion-saturation of metals is the gold standard. Titanium alloys easily absorb gases when heated above $250-300{ }^{\circ} \mathrm{C}$ [3]. This feature of titanium alloys also limits the type of working gases that can be used during heat treatment, as the introduction of nitrogen, oxygen or hydrogen into the surface should 
be reduced to a minimum. The formation of an alpha case should be avoided [6-8]. On the other hand, for particular aerospace applications, surface saturation by oxygen during anodizing has a beneficial effect on lubrication and wear resistance $[9,10]$. Therefore, it is possible to apply a thermochemical treatment, which leads to controlled surface saturation with interstitial atoms, e.g., nitrogen, to increase wear resistance in certain locations requiring this.

Increased demand for titanium for the aerospace industry and its strict weight-saving requirements have forced the constant development of Ti alloys. Nowadays, the two-phase high-strength BT22 titanium alloy, developed by the Russian Institute of Aeronautical Materials [11,12] (a modification of the Ti-5553 alloy [13-15]), has replaced both BT6 (Ti-64) and Ti-1023 (Table 1) titanium alloys for high-load applications [16,17]. Compared with BT6 and Ti-1023, BT22 is characterized by higher corrosion and heat resistance, improved ease of handling and advantageous machinability and weldability [18]. The high strength of the BT22 alloy, obtained after solid solution treatment and aging, was reported in $[19,20]$. The combination of a solid solution treatment and aging resulted in an $\alpha+\beta$ microstructure, providing both high strength and good ductility. It is possible to anneal it in the $\beta$ of an $\alpha+\beta$ region $\left(700-850^{\circ} \mathrm{C}\right)$ and age it at different temperatures $\left(480-800{ }^{\circ} \mathrm{C}\right)$ [11]. Alterations of the amount and size of the $\alpha$ phase result in an alloy strength in the range of 1100-1300 MPa [11-15].

Table 1. Composition of some $\alpha+\beta$ titanium alloys.

\begin{tabular}{|c|c|c|c|c|c|c|c|c|}
\hline Alloy & Al & $\mathbf{V}$ & Mo & $\mathrm{Cr}$ & $\mathrm{Fe}$ & $\mathrm{Zr}$ & $\mathrm{Nb}$ & Properties \\
\hline BT6 & 6 & 4 & - & - & $<0.3$ & $<0.3$ & - & UTS $850-1100 \mathrm{MPa}, 4-13 \%$ elongation \\
\hline Ti-64 & 6 & 4 & - & - & $<0.4$ & - & - & $\begin{array}{l}\text { High strength, cryogenic to } 427^{\circ} \mathrm{C} \\
\text { temperature range, UTS } 1100 \mathrm{MPa} \text {, } \\
10 \% \text { telongation }\end{array}$ \\
\hline BT22 & 5.2 & 4.8 & 4.8 & 1.2 & 1 & $<0.3$ & - & $\begin{array}{l}\text { UTS } 1100-1400 \mathrm{MPa} \text {, good } \\
\text { machinability and weldability, } \\
\text { elongation } 10 \%\end{array}$ \\
\hline Ti-5553 & 5 & 5 & 5 & 3 & & & - & $\begin{array}{l}\text { UTS } 1260 \mathrm{MPa}, 5-12 \% \text { elongation, high } \\
\text { fracture toughness }\end{array}$ \\
\hline Ti-55531 & 5 & 5 & 5 & 3 & 0.5 & 1.5 & - & UTS $1250 \mathrm{MPa}$ \\
\hline Ti-1023 & 3 & 10 & - & - & 2 & - & - & UTS $1100-1300 \mathrm{MPa}, 5-12 \%$ elongation \\
\hline Ti-5321 & 5 & 3 & 3 & 2 & 2 & 2 & 1 & UTS $1147-1439 \mathrm{MPa}, 3-26 \%$ elongation \\
\hline
\end{tabular}

An alloy similar to BT22, Ti-55531, a modification of the alloy Ti-5553, was studied by [21-23]. Its mechanical properties can be altered by a variation in the nucleation process of an $\alpha$-phase. Moreover, the niobium- and zirconium-modified alloy Ti-5321 of a Ti-Al-Mo$V$ system is stronger than most other $\beta$ and near- $\beta$ alloys and can also be used to replace both Ti-1023 and Ti-64 [24,25].

The nucleation of the ultrafine $\alpha$ phase in an experimental double-phase titanium alloy, Ti-64-57 (a Ti-64 alloy modified by 5Mo and 7Zr), from $\alpha^{\prime \prime}$, obtained as a result of quenching, produces more $\alpha / \beta$ interphases [26]. This forces dislocations to climb and block, therefore significantly increasing the alloy's strength [27].

As one can see, a variety of newly developed high-strength alloys similar to BT22 have been developed and are readily available for use within aerospace applications, e.g., flap tracks, airframe linkage units and landing gear struts [11-21,23].

The mechanical properties and microstructures of these alloys are well known already [12-26], but their ability to be thermochemically processed has still not been discussed thoroughly enough. Some studies have been carried out on the BT22 alloy and the related family of alloys, mostly evaluating the impact of the process on the hardness and microstructure, not the wear resistance [27-29]. 
Therefore, our study proposed a method of improving the wear resistance of a heavyduty double-phase Ti-64, BT22 alloy by a duplex aging and thermochemical treatment. The tribological performance of the treated material was tested under dry sliding conditions in a pin on disc configuration. The study discusses both the coefficient of friction (COF) and the wear of the tribocouple. To support the results, SEM observations were used to determine the dominant wear modes of both treated and reference (non-heat-treated) samples. The results will allow academia and the industry to enhance the wear resistance of other $\beta$, near- $\beta$ and $\alpha+\beta$ alloys.

Of the reviewed alloys (Table 1), the most frequently used alloy is Ti-64. For structural and biomedical applications, many methods of surface strengthening can be applied [30,31]. The wear resistance properties of this alloy were studied in depth. The application of nitriding in BT22 alloy was studied in [32,33], and the results were very promising.

\section{Titanium Nitriding Methods: Drawbacks and Benefits}

\subsection{Plasma Nitriding}

Plasma nitriding methods typically provide high hardness and case depth to treated surfaces. Moreover, the process is known to smoothen the surface profile of the sample [34]. However, various sharp edges may be burnt or overheated due to a local increase in the surface temperature; nevertheless, plasma nitriding is widely used to enhance the wear resistance of titanium alloys and steels [34].

Taktak and Akbulut [35] investigated the wear resistance of the titanium alloy Ti-64, which was nitrided in a plasma medium after detonation explosive shock treatment (DEST). After nitriding at temperatures up to $900{ }^{\circ} \mathrm{C}$ for $12 \mathrm{~h}$, a maximum top surface hardness of $2500 \mathrm{HV}_{0.05}$. was reported. This value is much higher than found in other studies reviewed in this section. The authors did not explain it, but they probably obtained a dense compound layer consisting only of TiN due to the high strain induced by DEST. The wear tests showed [35] that nitriding significantly increases the wear resistance of titanium alloys. The primary wear mechanism of WC-Co vs. nitrided Ti-64 was fatigue-assisted abrasive wear.

Pure titanium was plasma-nitrided in [36]. The high hardness (1000-1300 $\mathrm{HV}_{0.1}$ due to the formation of super-hard $\varepsilon-\mathrm{Ti}_{2} \mathrm{~N}$ and $\delta$-TiN phases) and relatively low thickness (5-15 microns) created an unwanted sevenfold difference in hardness between the diffusion layer and the substrate. The high hardness values in $[35,36]$ may also be explained by the low load used for Vickers indentation. According to the authors of [36], plasma nitriding of pure Ti resulted in a significant reduction in COF.

Plasma nitriding of a Ti5A14V2Mo alloy in a mixture of nitrogen and argon [37] for $3-4 \mathrm{~h}$ at temperatures $500-900{ }^{\circ} \mathrm{C}$ produced a rather hard surface $\left(600-800 \mathrm{HV}_{0.05}\right)$. Thus, we can conclude that using argon and reduced pressure does not promote significant layer thickness and hardness. In other work [38], a Grade 2 titanium alloy was plasma-nitrided at $650-950{ }^{\circ} \mathrm{C}$ (with $50{ }^{\circ} \mathrm{C}$ increments) for $8 \mathrm{~h}$. The maximum surface hardness $\left(1550 \mathrm{HV}_{0.05}\right)$ and layer thickness (about $55 \mu \mathrm{m}$ ) were reported for plasma nitriding at $950{ }^{\circ} \mathrm{C}$. However, increasing the nitriding temperature above $850{ }^{\circ} \mathrm{C}$ reduces the wear resistance of the alloy.

Plasma nitriding using an $\mathrm{N}_{2}-\mathrm{NH}_{3}$ gas mixture at temperatures of 700 and $750{ }^{\circ} \mathrm{C}$ was studied by Shen and Wang [39]. According to the results provided, a $2.3 \mu \mathrm{m}$ compound layer for $\mathrm{NH}_{3}$ and a $6.5 \mu \mathrm{m}$ compound layer for the $\mathrm{N}_{2}-\mathrm{NH}_{3}$ gaseous mixture was obtained, which is much less than that achieved at higher temperatures.

Plasma nitriding provides the greatest layer thickness and hardness when applied at temperatures above $850^{\circ} \mathrm{C}$. Low-temperature plasma nitriding does not lead to high thickness or hardness in the modified layers. Plasma nitriding is quite a complicated method. It requires sophisticated equipment [35-37] and cannot always be reproduced in common manufacturing conditions. It greatly improves corrosion resistance. The best wear resistance was reported in plasma-nitrided Ti alloys for specimens treated at a temperature range of $800-850{ }^{\circ} \mathrm{C}$ [38]. Increasing the temperature of plasma nitriding from 700 to $850{ }^{\circ} \mathrm{C}$ improves the wear resistance $[38,39]$. On the other hand, reducing the 
process temperature reduces the surface roughness [36] and the coefficient of friction, thus increasing the wear resistance $[35,39]$. Moreover, a low-temperature process can improve the corrosion resistance of an alloy by creating a protective barrier [40].

\subsection{Laser-Assisted Nitriding}

For titanium alloys, the novel plasma-enhanced pulsed-laser deposition system [41] allows one to obtain a relatively thin nitride layer (more than $100 \mathrm{~nm}$ over $1 \mathrm{~h}$ ), which is not very effective. Compared with plasma nitriding, laser-assisted gas nitriding [42] requires much more power (1-5 kW vs. 400-650 W [36]) for processing. Moreover, the plasma nitriding method treats all the exposed surfaces, while laser-assisted methods affect only the scanned surfaces. However, they may be used for selectively treated areas and textured surfaces [43] or thermocycled coatings [44,45]. While laser nitriding involves surface remelting and requires precise control of the saturation parameters, it is also hard to process internal surfaces via this method (e.g., holes for the insertion of bronze landing gear bushings). Obtaining a thick coating is not always possible, but their effective production has been reported [46].

\subsection{Gas-Blow Induction Heating Nitriding Method}

Induction heating of a Ti64 alloy in a nitrogen atmosphere generates a nitrided layer in only a few minutes [47]. The best wear resistance of the alloy is observed when the treatment temperature is $900{ }^{\circ} \mathrm{C}$, as both compound and diffusion layers are formed. Nevertheless, at this temperature, coarsening of the microstructure may be observed, which has an adverse effect on the alloy's mechanical properties. Moreover, the authors of [48] removed the compound layer and discovered that this improved the fatigue resistance while reducing the wear resistance.

Low temperatures $\left(650{ }^{\circ} \mathrm{C}\right)$ during gas-blow induction heating nitriding after shot peening with fine particles produce both diffusion and compound layers in a relatively short exposure time. The hardness of treated Ti-64 specimens is $400-450 \mathrm{HV}_{0.025}$, which is low. However, the highest substrate temperature can be observed not on the top of the sample but in the sublayer because the surface is cooled by gas flow during the induction heating process $[49,50]$. The gas-blow induction heating nitriding process has potential as a rapid nitriding technology, but it should be studied much more thoroughly than it has been to date.

\subsection{Electron-Beam Vacuum Nitriding}

This newly introduced method [51,52] uses an electron beam for nitriding under low (8-10 Pa) pressure. Pure titanium was used to manufacture the test specimens, and the results were quite positive. The strengthened layer thickness was $15-35 \mu \mathrm{m}$, and the surface micro hardness measured by the Vickers method at a load of $0.1 \mathrm{~kg}$ was up to $12 \mathrm{GPa}$ $\left(\approx 1200 \mathrm{HV}_{0.1}\right)$. Though this technology may have a future as a type of plasma nitriding, it is necessary to develop it further for aerospace applications.

\subsection{Gas Nitriding}

Gas nitriding is probably the simplest of all nitriding methods. It requires only a furnace under good pressure control at the specified temperature ranges. The dynamic gas flow allows internal surfaces to be treated with the same efficiency as flat specimens. The nonoxidizing atmosphere during gas nitriding allows the heat treatment of the alloy in one step with thermochemical processing [31,32].

Gas nitriding was used to study the strengthening of the newly developed TZ20 (Ti-19.2Zr-6.48Al-3.86V-Hf-Na) alloy [53]. Increasing the temperature from 500 to $650{ }^{\circ} \mathrm{C}$ increased the weight gain from 0.62 to $3.67 \mathrm{mg} / \mathrm{cm}^{2}$ (592\%). The duration of the process was $260 \mathrm{~min}$, and the nitrogen pressure in the reaction chamber was $0.05 \mathrm{MPa}$. The nitrided layer's thickness was $1-7 \mu \mathrm{m}$ after $1 \mathrm{~h}$, and the maximum value was $12-14 \mu \mathrm{m}$. The surface hardness increased from $470 \mathrm{HV}_{0.01}$ to $870 \mathrm{HV}_{0.01}$. In another study [54], 
intermittent vacuum nitriding of a TB8 (Ti-15.32Mo-3.23Al-2.86Nb) alloy at $780{ }^{\circ} \mathrm{C}$ gave much better results: a hardness of $850-900 \mathrm{HV}_{0.1}$ and a nitride layer thickness of up to $120 \mu \mathrm{m}$. We may conclude that an increase in temperature and nitrogen gas pressure results in a thicker compound layer and higher hardness, but this also strongly depends on the alloy's composition. The influence of higher temperatures under atmospheric pressure is presented in [55]: increasing the temperature and exposure time resulted in thicker and harder surfaces. A method of gas nitriding in an ammonia medium also produced good results $[39,56]$ : at $1100{ }^{\circ} \mathrm{C}$ and atmospheric pressure, the layer's thickness was $40-50 \mu \mathrm{m}$ after $5 \mathrm{~h}$.

Gas nitriding is not effective for $\beta$-titanium alloys but is good for double-phase alloys in the region of the $\beta$-transus temperature [57]. Vacuum preheating has a beneficial effect on the gas nitriding process [58]. This helps to remove oxygen and other gaseous impurities from the surface and facilitates the thermal diffusion process. Regarding the BT22 titanium alloy, the standard heat treatment combines diffusion annealing [11] from the betta region $\left(750-850{ }^{\circ} \mathrm{C}\right)$ and slow cooling. This results in a uniform microstructure with a good combination of mechanical properties. High strength (up to UTS $1400 \mathrm{MPa}$ ) may be obtained after aging. This alloy may be used both in annealed and aged conditions.

Based on this analysis of nitriding's effects on the surface layer's properties [35-42,44-59], we decided to study gas nitriding of the double-phase high-strength BT22 titanium alloy. As higher temperatures and gas pressure results in thicker and harder surfaces, the process parameters selected are an atmospheric nitrogen pressure and temperature range of $750-850{ }^{\circ} \mathrm{C}$. A slow temperature increase in a vacuum before nitriding is assumed to have the same effect as preheating [58].

\section{Materials and Methods}

Samples of a high-strength $(\alpha+\beta)$ titanium BT22 alloy (Ti-5Al-4.75Mo-4.75V-1Cr$1 \mathrm{Fe})$ [12] were studied. The concentration of $\beta$-stabilizing elements was $K_{\beta \sim} 1.0$ [11].

The discs (samples) had a diameter of $55 \mathrm{~mm}$ and a height of $5 \mathrm{~mm}$. The pin counterparts had a diameter of $8 \mathrm{~mm}$ and a length of $10 \mathrm{~mm}$ (the BT22 material in as-supplied condition). The friction surfaces of the discs (before thermochemical processing) and pins were ground to a roughness of $R_{a} 0.53 \mu \mathrm{m}$. Discs were degreased in an ultrasonic alcohol bath before the nitriding and wear tests.

The discs' and pins' dimensions and the "all-over" treatment of discs made it possible to perform four separate tests on each sample (See Figure 1b,c).

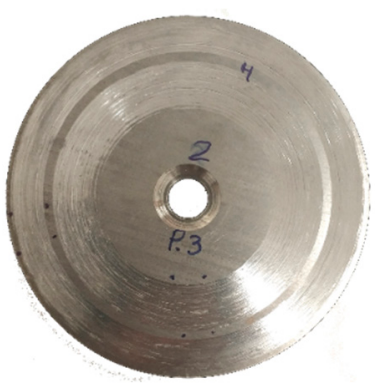

(a)

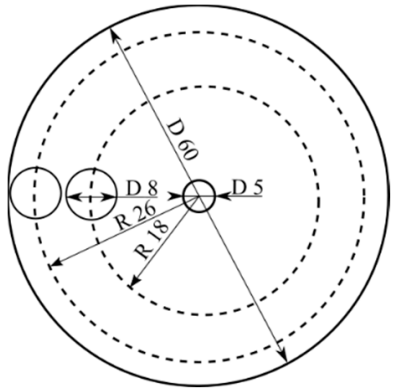

(b)

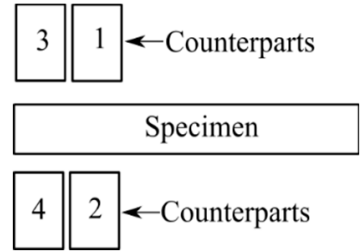

(c)

Figure 1. Positioning of the specimens and pin counterparts: (a)—tested specimens, $(\mathbf{b}, \mathbf{c})$ - dimensions and positioning of the counterparts on the disc surfaces and the order of the wear tests.

The details of thermochemical processing are shown in Figure 2. Before the heating started, the air was evacuated from the furnace, reaching a vacuum of $10 \mu \mathrm{Pa}$ to remove the oxide film and reduce the presence of oxygen and hydrogen. 


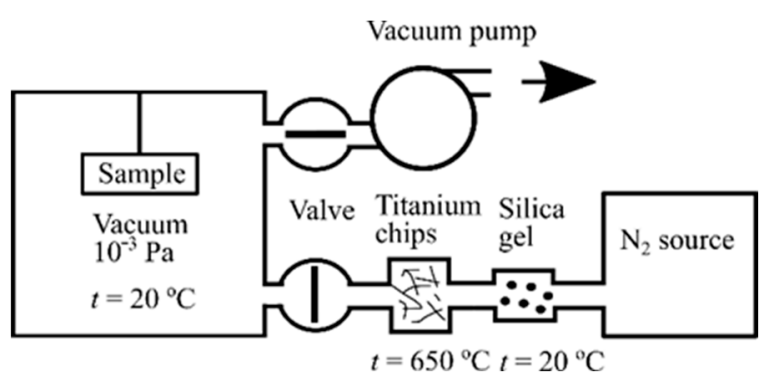

(a)

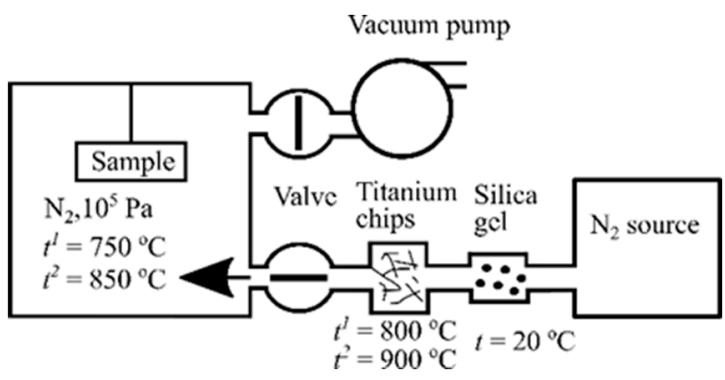

(b)

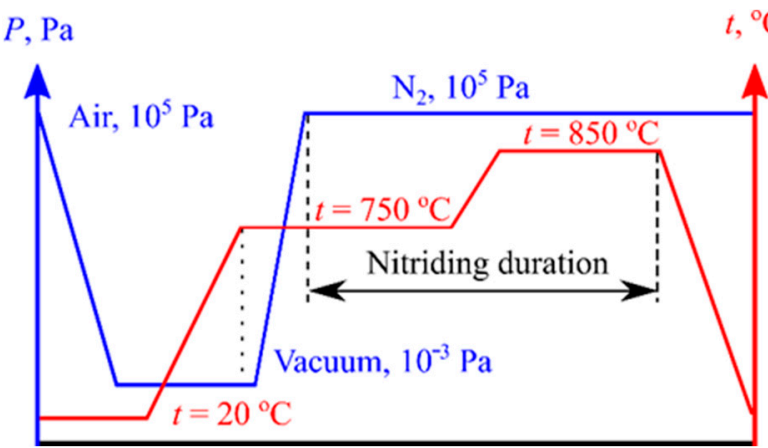

(c)

Figure 2. Titanium BT22 nitriding procedure: (a) - furnace is prepared for thermochemical processing; (b) - double-step nitriding process, (c) — temperature and pressure graphs during the heat treatment procedure.

Before the first aging stage, the nitrogen was let into the furnace until the pressure reached $\mathrm{P}_{\mathrm{N} 2}=10^{5} \mathrm{~Pa}$. To utilize pure nitrogen, we passed it through a box with silica gel (to remove water; ambient temperature) and a gas trapper (a box with titanium chips heated to $\mathrm{t}^{1}=800{ }^{\circ} \mathrm{C}$ and $\mathrm{t}^{2}=900{ }^{\circ} \mathrm{C}$ ). After each treatment procedure, the titanium chips were replaced, and the silica gel was vacuum-baked at $180{ }^{\circ} \mathrm{C}$ for $2 \mathrm{~h}$. Next, aging at $750{ }^{\circ} \mathrm{C}$ was applied for $4 \mathrm{~h}$, followed by aging at $850{ }^{\circ} \mathrm{C}$ for $4 \mathrm{~h}$ with the simultaneous diffusion saturation of the surface in the nitrogen atmosphere.

The microstructure was studied before and after nitriding in normal sections. The hardness and microstructure of the nitride layer were studied on tapered sections (Figure 3). The sample was cut apart, then one of the parts was polished and etched for microstructural examinations; the other one was only polished and used for microhardness tests. Etching created a somewhat rough surface, and this reduced the repeatability and accuracy of measurements. Moreover, placing the indentations in multiple lines (Figure 1b) allowed to keep an appropriate distance between them and to get any desired vertical pitch. The tapered section made the nitrided layer thicker and facilitated the study.

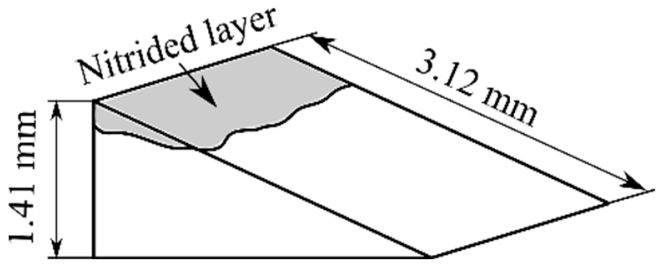

(a)

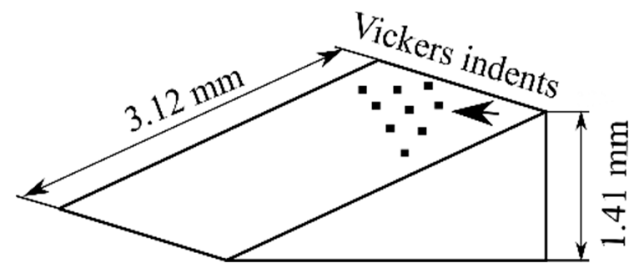

(b)

Figure 3. Schematic of the method of sample preparation for microstructural studies (a) and microhardness tests $(\mathbf{b})$.

To treat the surface, Kroll's reagent with the following composition was used for etching: $5 \%$ of $\mathrm{HNO}_{3}, 3 \%$ of $\mathrm{HF}$ and $92 \%$ of $\mathrm{H}_{2} \mathrm{O}$. For the phase analyses of the nitrided 
surface, a DRON-3.0 X-ray diffractometer was utilized (Bregg-Brentano $2 \theta$ configuration, monochromatic $\mathrm{Cu} \mathrm{K} \alpha$ radiation).

The microstructure of the modified layers of titanium alloys were examined using an optical microscope. For investigating the detailed microstructural and wear tracks, an SEM-FIB DualBeam Scios 2 (Thermo Scientific, USA) was used. Vickers microhardness was measured with a PMT-3M instrument under an indenter load of $10 \mathrm{~g}$. The nitrided layer's thickness was measured by the metallographic and hardness profile methods [59].

We used a T11 pin-on-disc tribometer for the wear tests. Samples were weighed before and after the experiment using Radwag XA/210Y analytical balances with an accuracy of $0.01 \mathrm{mg}$. As the pins' installation diameter $\mathrm{R}$ values (see Figure 1c) were dissimilar (26 and $18 \mathrm{~mm}$ ), the rpm was adjusted (266 and 184 respectively) to provide a constant sliding speed of $0.5 \mathrm{~m} / \mathrm{s}$ and a sliding distance of $300 \mathrm{~m}$ and contact pressure of $0.2 \mathrm{MPa}$.

\section{Results}

\subsection{Microstructure and Phase Analyses}

After nitriding, the surface color changed from silvery to yellow-gold, indicating the presence of titanium nitrides [53]. The results of the XRD studies are shown in Figure 4 and Table 2.

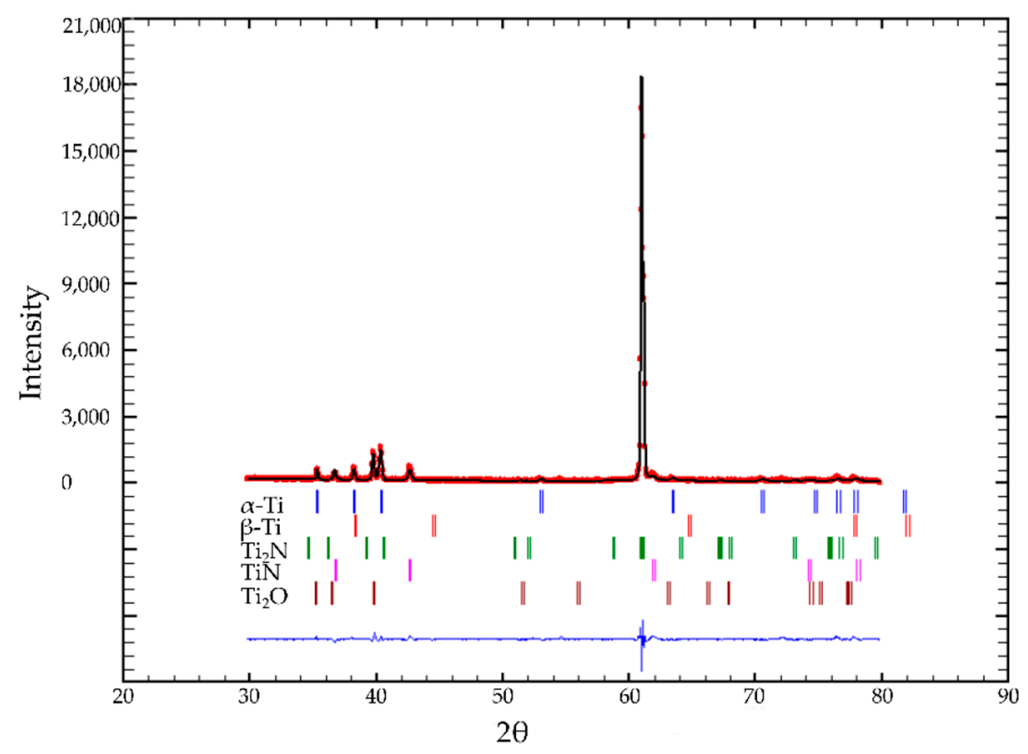

Figure 4. X-ray diffraction pattern of the nitrided surface.

Table 2. Phase composition and lattice parameters of the nitrided surface.

\begin{tabular}{cccccc}
\hline \multirow{2}{*}{ Phase } & \multicolumn{3}{c}{ Lattice Parameter } & \multirow{2}{*}{ Space Group } & \multirow{2}{*}{ o } \\
\cline { 2 - 4 } & $\mathbf{a}$ & $\mathbf{b}$ & $\mathbf{c}$ & & \\
\hline$\alpha-\mathrm{Ti}$ & $2.9334(1)$ & $2.9334(1)$ & $4.7120(9)$ & P63/mmc & 12.39 \\
\hline$\beta-\mathrm{Ti}$ & $4.0703(9)$ & $4.0703(9)$ & $4.0703(9)$ & Fm-3m & 1.34 \\
\hline $\mathrm{Ti}_{2} \mathrm{~N}$ & $4.9697(4)$ & $4.9697(4)$ & $3.0356(9)$ & $\mathrm{P} 42 / \mathrm{mnm}$ & 68.06 \\
\hline $\mathrm{TiN}^{2}$ & $4.2392(8)$ & $4.2392(8)$ & $4.2392(8)$ & Fm-3m & 9.29 \\
\hline $\mathrm{Ti}_{2} \mathrm{O}$ & $2.9458(1)$ & $2.9458(1)$ & $4.9311(8)$ & P-3m1 & 8.92 \\
\hline
\end{tabular}

Therefore, the nitride layer predominantly consisted of unsaturated $\mathrm{Ti}_{2} \mathrm{~N}$, with a minor presence of $\mathrm{TiN}$ and $\mathrm{Ti}_{2} \mathrm{O}$. The formation of a single-phase TiN compound layer was avoided.

Figure $5 \mathrm{a}, \mathrm{b}$ show two micrographs of the alloy obtained before heat treatment (light field: $\alpha$ phase; dark field: $\beta$ phase. There are two types of $\alpha$-particles present in Figure $5 b$ : 
coarse and fine. The coarse grain boundary phase (red arrows) had a length of 10-60 $\mu \mathrm{m}$ and a thickness of $1-3 \mu \mathrm{m}$. Fine randomly oriented $\alpha$ colonies inside the $\beta$ grains (yellow arrows) had a length of 3-20 $\mu \mathrm{m}$ and a thickness typically less than $1 \mu \mathrm{m}$. This microstructure is common for BT22 alloys in annealed equilibrium (as supplied) conditions [11]. The grain boundary $\alpha$ phase helps in measuring the average $\beta$ grain size: $30-50 \mu \mathrm{m}$. The content of the $\alpha$ phase nearly equaled the quantity of the $\beta$ phase (the $\beta$-phase content was $45-52 \%$ ). The measured hardness of the material was $300 \mathrm{HV}_{0.01}$.

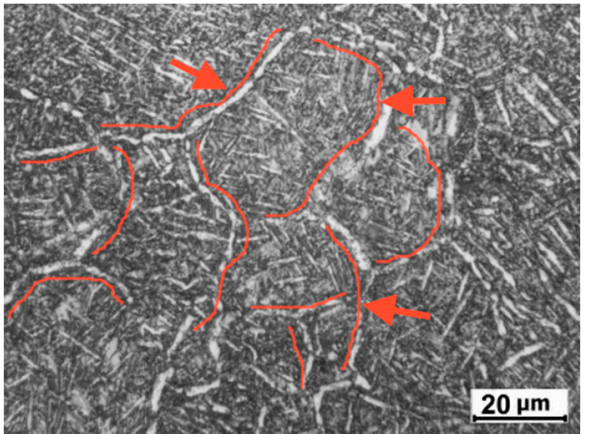

(a)

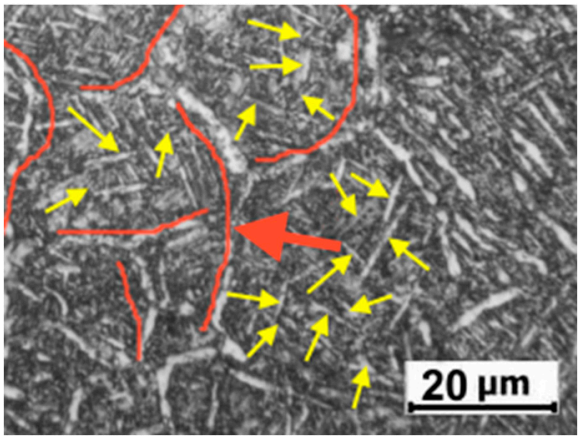

(b)

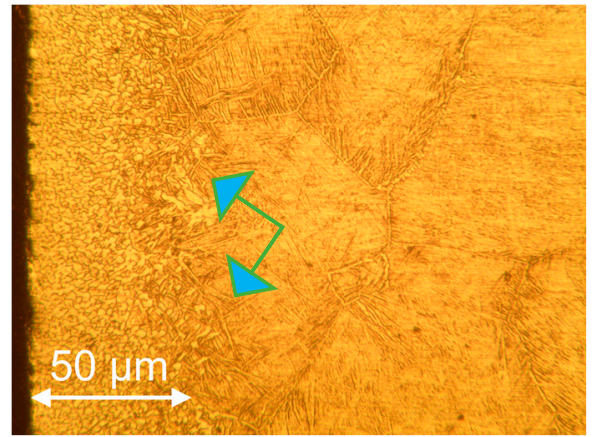

(c)

Figure 5. Microstructure of the BT22 alloy: (a) $\alpha$ phase on the boundaries of $\beta$ grains, in the assupplied condition; (b) randomly oriented $\alpha$ phase inside $\beta$ grains, in the as-supplied condition; (c) after nitriding. The arrows show the boundary of the nitrided layer.

The microstructure of the alloy after double-step nitriding is presented in Figure 5c. The thickness of the nitrided layer was $50 \mu \mathrm{m}$ (the scale of Figure $5 \mathrm{c}$ is recalculated, taking into account the oblique section geometry, see Figure 1a). The $\alpha$ phase particles became finer (as seen in Figure 5a,c) and led to an increase in the alloy's surface hardness up to $1190 \mathrm{HV}_{0.01}$ (Figure 6). As the grain boundary phase changed its morphology, it was hard to measure the size of the $\beta$ grains.

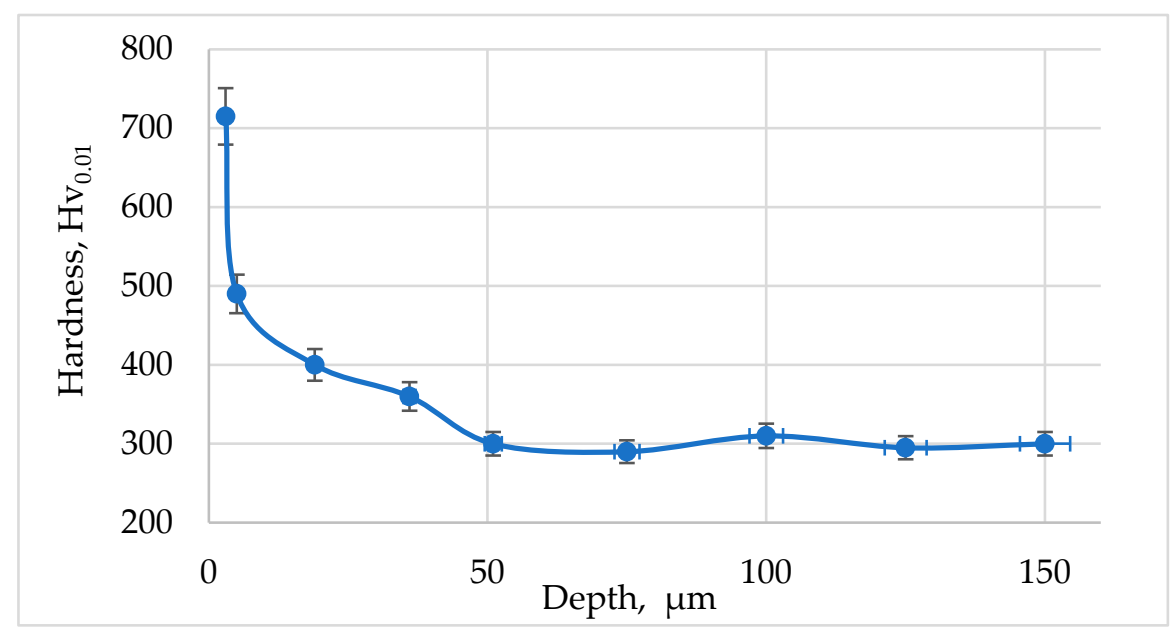

(a)

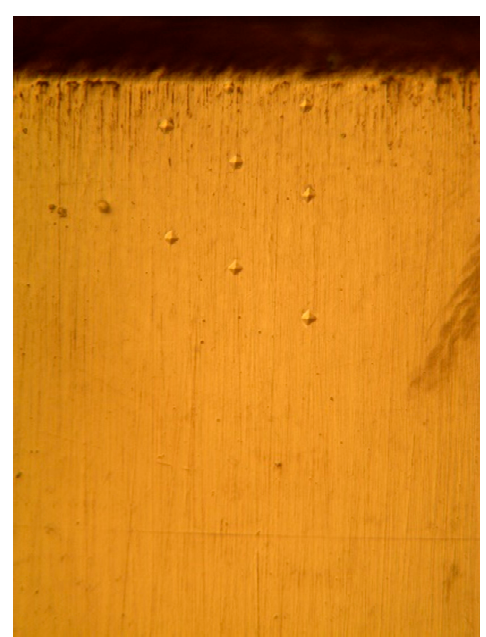

(b)

Figure 6. Hardness profile of the nitrided BT22 alloy (a) and the oblique section with indents (b).

\subsection{Hardness}

The microhardness measurements indicated that the thickness of the thermodiffusion layer was $40-50 \mu \mathrm{m}$, which is typical for this surface strengthening technology. The surface hardness was uniform, which is evidence of a stable saturation process with a modified layer of the same thickness over the specimen. The hardness results of the three specimens (mean values $+\mathrm{SD}$ ) are presented in Figure 6. Additionally, three indentations to measure 
the surface hardness were made on the top of each sample. The subsurface microhardness was $715 \mathrm{HV}_{0.01}$. Similarly, metallographic studies indicated the same thickness of the nitrided layer: $40-50 \mu \mathrm{m}$. The hardness of the untreated material was $300 \mathrm{HV}_{0.01}$.

The maximum surface hardness achieved by the method was $1190 \mathrm{HV}_{0.01}$, which is more than that found for the method described in [37] for the titanium alloy Ti5Al4V2Mo (600-800 $\left.\mathrm{HV}_{0.05}\right)$, roughly the same as that in [33] $\left(1550 \mathrm{HV}_{0.05}\right)$ and [29] $\left(1000-1300 \mathrm{HV}_{0.1}\right)$, but less than the $2500 \mathrm{HV}_{0.05}$ found in [28]. It should also be mentioned that lower loads during the microhardness test produced greater hardness as the indenter pierces the thinner top layer of the alloy. Naturally, this top layer has higher hardness. To compare the hardness profile, the strengthened layer's thickness were nearly the same as in $[38,41,55]$ (in the range of $15-50 \mu \mathrm{m}$ ) but less than that found in [53], namely $120 \mu \mathrm{m}$.

\subsection{Wear Resistance Test}

Specimens were tested separately, with four tests per specimen condition. The test results are shown in Figure 7. The mean wear loss of the untreated titanium alloy was $16.55 \mu \mathrm{g}$, and the mean wear loss of the nitrided alloy was $8.24 \mu \mathrm{g}$ (mean value + SD). Therefore, the nitrided alloy is superior when compared with untreated material by a magnitude of 2 . The nitrided layer separates the friction surfaces, created by a natural or friction-induced oxide film [60], thus preventing contact between the two metals.

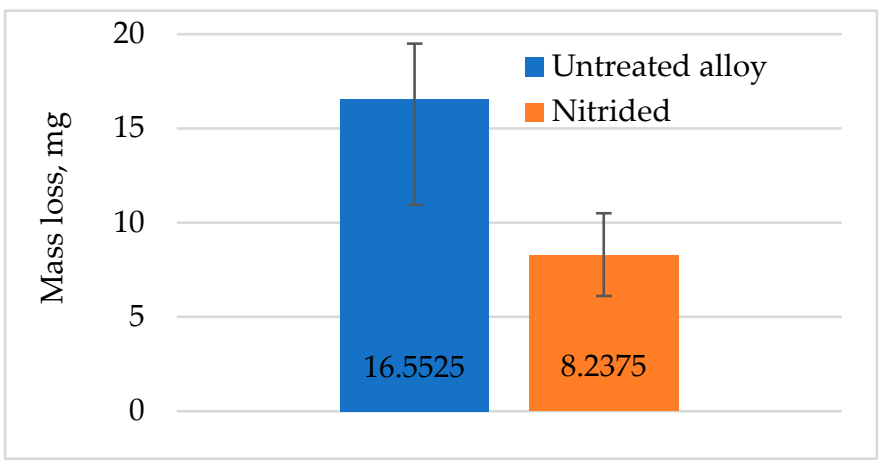

Figure 7. Wear loss of tested specimens.

The friction coefficient (COF) values are given in Figure 8. As one can see, regardless of the nitriding treatment applied, after saturating the BT22 alloy's surface with nitrogen, the variation reduced, and the average COF value dropped from 0.6 to 0.5 . This is also reflected in the weight loss of the samples (Figure 7), where a clear advantage of nitriding over nontreated samples can be seen.

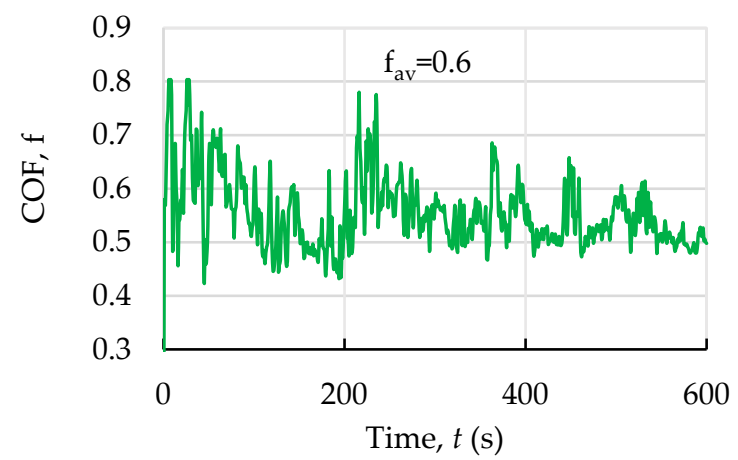

(a)

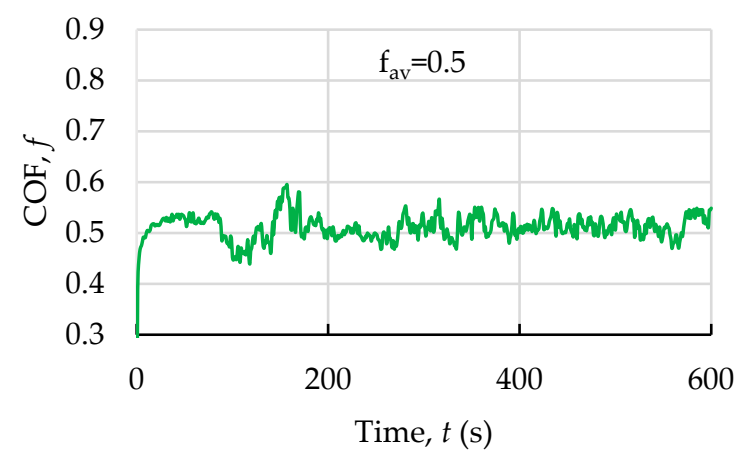

(b)

Figure 8. Friction factor diagrams of the studied BT22 alloy: (a) as manufactured, no treatment; (b) after nitriding. 


\subsection{The Wear Tracks' Topography}

The wear track analyses indicated a substantial difference in the dominant wear modes between the nontreated and the duplex-treated samples (Figure 9). The untreated alloy's wear track topography is given in Figure 9a. The general appearance of the friction surface indicates nonuniform wear with signs of deformation, metal flow, adhesive wear and scuffing. On the other hand, in the duplex-treated sample (Figure 9b), the dominant wear mode is abrasive wear, was accompanied by plowing. In some spots, the diffusion layer may be seen, which proves that some of the layers survived the dry friction test.

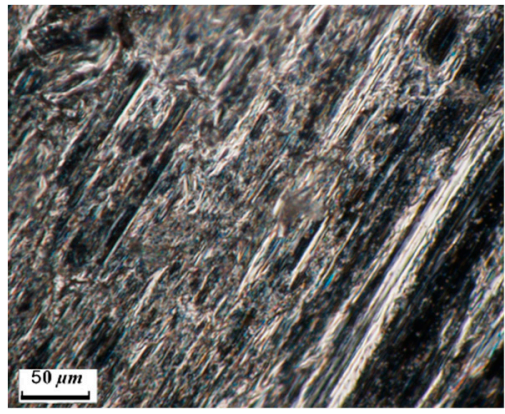

(a)

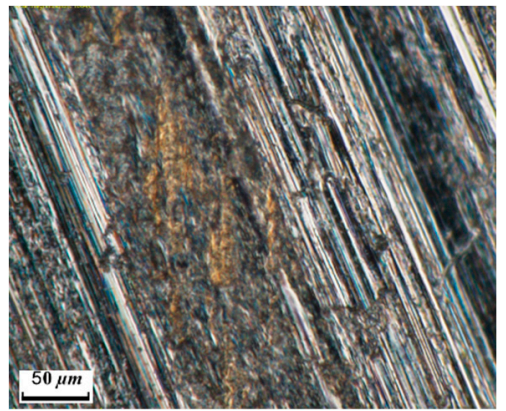

(b)

Figure 9. Wear tracks of the BT22 alloy: (a) untreated; (b) nitrided (light microscopy).

More detailed studies of the surfaces were carried out using SEM. Figures 10 and 11 compare the wear scars of the materials. On the surface of the untreated alloy (Figure 10a), signs of plowing and metal outflows are intensive, although the area around this portion seems to be undamaged. The high-magnification image indicates the formation of secondary frictional layers on the surface, which may have originated from both the parent or the counterpart material (Figure 10b). However, it is challenging to claim whether the counterpart material was adhesively transferred because the substrate was self-mated (untreated BT22). Figure 10c indicates the intensive cold plastic deformation of the surface layer and the metal portions beginning to delaminate (arrowed). We may suppose that in this case, most of the wear particles formed as a result of deformed metal tears flowing out of the actual friction contact sites (see Figure 10d). Moreover, some wear debris was shaped by repeated rolling between the discs' and counterparts' surfaces (Figure 10e). Such spheres are supposed to be harder than the parent material and are capable of causing damage, as seen in Figure 8a.

On the contrary, the surface of the nitrided specimen's wear track was flat (Figure 11a). The actual contact occurs more often along lighter strips of the surface, containing less nitrogen (due to the worn-off top layer). The black spots present in Figure 11a indicate the wear products. Details are shown in Figure 11d,e. Figure $9 \mathrm{~b}$ indicates a possible brittle fracture in the surface. As the images were taken in BSE mode, the brighter areas correspond to the metallic substrate, while the areas saturated with nitrogen atoms are represented by the darker areas. The nature of other light spots around this area originated from their counterparts but not the substrate material. This place may be one of the few sites of adhesion wear typical of untreated titanium alloys [61].

Moreover, some plastic deformation and smearing of the Ti alloy can be seen, along with places of interest appearing as light spots on the surface. They contain a minimum of light elements ( $\mathrm{N}$ and $\mathrm{O}$ ) and may be formed due to adhesion and material transfer from their counterparts (untreated BT22). The size of powdery wear debris is $0.2-1 \mu \mathrm{m}$, with some coarser $3 \mu \mathrm{m}$ particles covering the recesses and other "friction-free" parts of the surface (Figure 11d,e). Wear debris on the surface is darker than the sublayer (Figure 11e). The debris mainly resulted from the deterioration of the nitrided layer. The arrows show areas of further surface destruction and the formation of new wear particles. Their sharp edges contribute to increased wear loss. Their dimensions are close to the width of the 
grooves. They may also be impregnated into the soft counterpart surface, creating even more severe friction conditions.

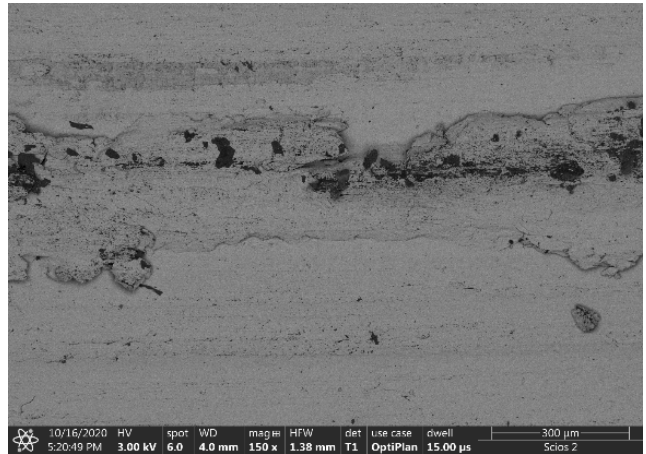

(a)

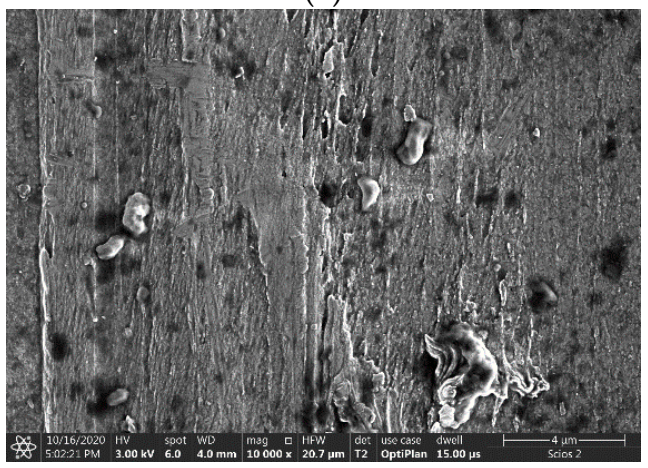

(b)

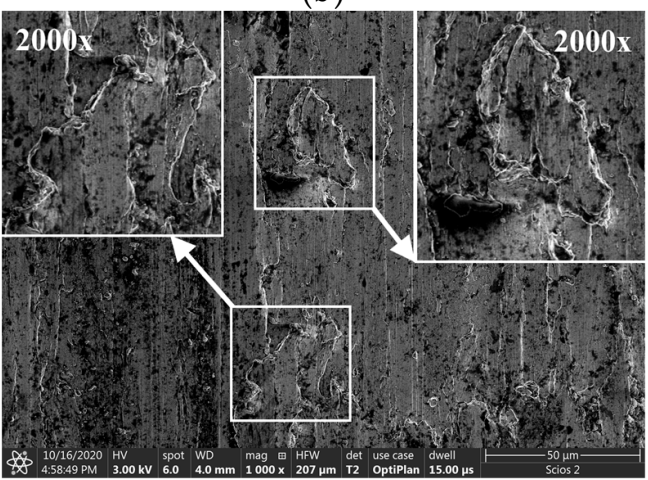

(c)

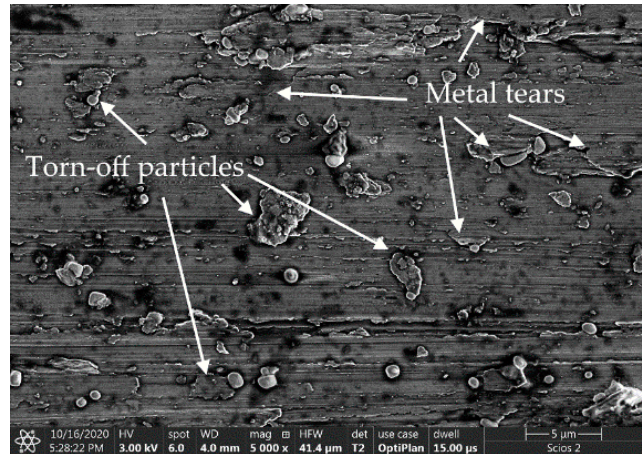

(d)

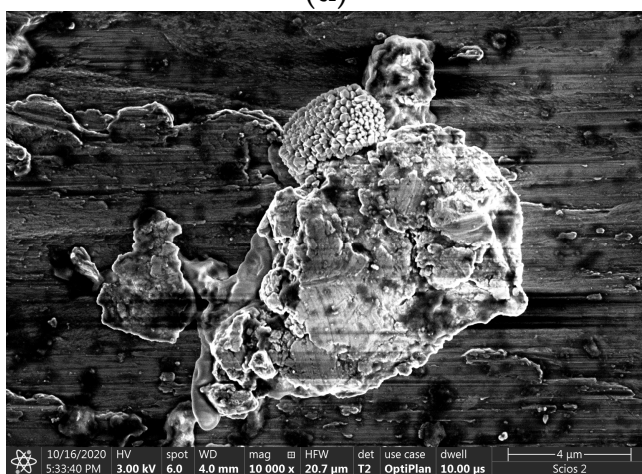

(e)

Figure 10. The topography of the wear tracks of the as-fabricated (untreated) BT22 alloy: (a) signs of plowing and metal outflows; (b) formation of secondary frictional layers on the surface; (c) intensive cold plastic deformation and beginning of delamination; (d) formation of metal tears and wear particles; (e) rolled wear particles. 


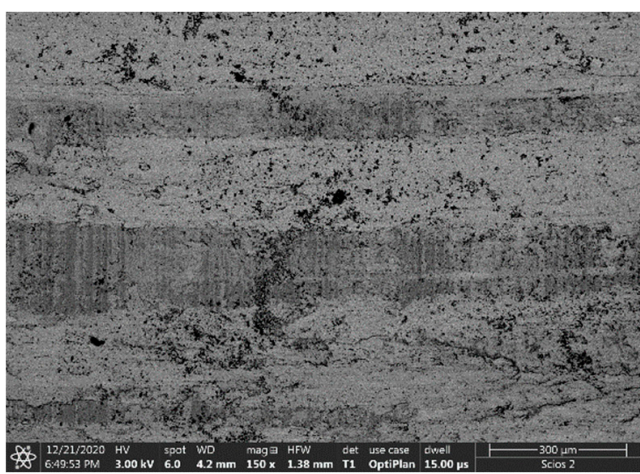

(a)

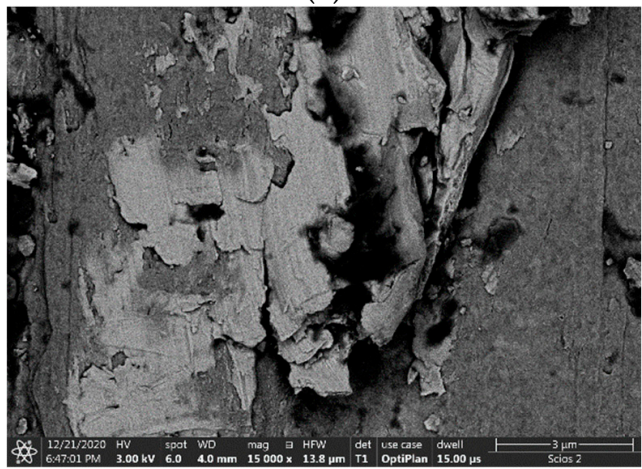

(b)

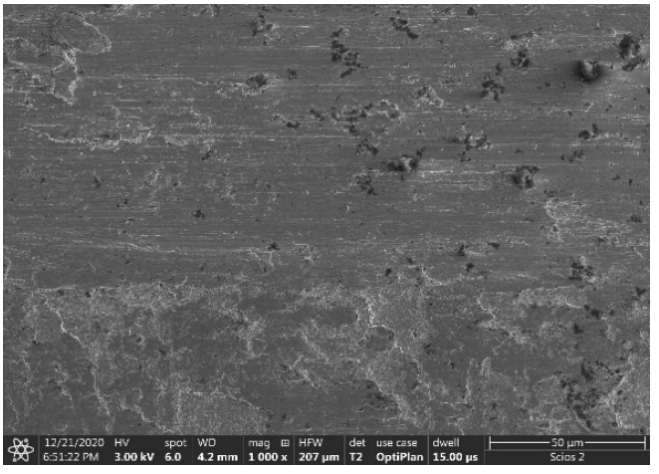

(c)

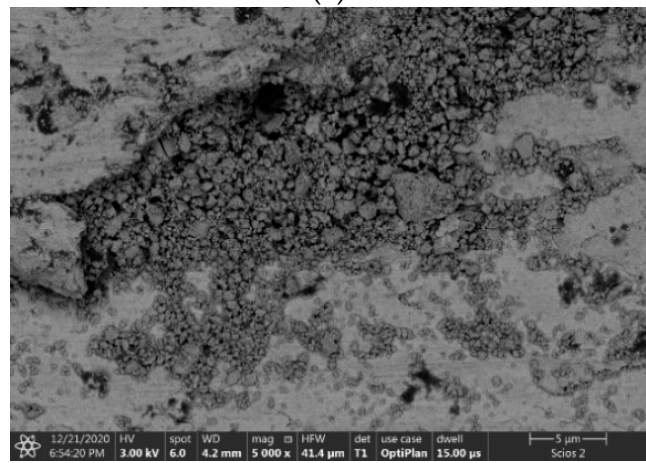

(d)

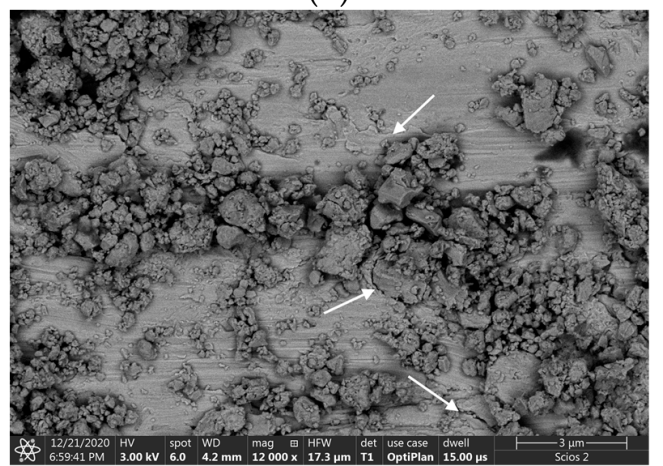

(e)

Figure 11. The topography of the wear tracks of nitrided alloy BT22: (a) flat wear surface of nitride specimen; (b) signs of surface brittle fracture; (c) minor metal outflows in lower part of the image; (d) fine wear particles; (e) wear particles and minor metal outflows (arrowed).

\section{Discussion}

The composition, microstructure and microhardness of the surface layer, which had a high amount of $\mathrm{Ti}_{2} \mathrm{O}$, posed a question regarding the oxygen source. We suppose that the source was the natural oxide film on the surface of the alloy and that some other amount was added from the nitrogen or during the cutting of the alloy into discs. Nevertheless, its presence is considered to be beneficial, as it might decrease the hardness and brittleness of the surface. It was reported in [62] that relatively soft titanium oxidides behave as solid lubricants. The hardness of $\mathrm{Ti}_{2} \mathrm{~N}$ is also much lower than that of $\mathrm{TN}$, and this has a positive effect on the wear resistance [63].

The coefficient of the friction of the untreated BT22 alloy in the current study was 0.6 , and that of the nitrided alloy was 0.5. This is much higher than the value of 0.25 in [36] and nearly the same as the result in [35] (0.45). In other studies, the reported COF was 0.6-0.7 [42], which is within the confidence interval (0.25-0.7). Compared with the untreated alloy, nitriding during aging provided stable and lower values for the coefficient of friction and doubled the wear loss reduction (Figures 7 and 8). The maximum value of 
the friction coefficient for the untreated alloy was 0.8 . This may be evidence of adhesion wear. In Figure 8a, one may see an initial rapid increase in the COF of the untreated alloy. The natural oxide film wears off from both the specimen and the counterpart at the initial moment of friction. Oxide-free metallic surfaces firmly adhere to each other. When the friction process becomes stable, the friction-induced oxide film separates the surfaces, and the coefficient of friction drops to lower values. The other reason for the high friction coefficient is the deformation of initial surface asperities and the increased number of contact points on the matting surfaces [64]. For nitrided specimens, the diffusion layer was strong enough and protected the surfaces from free metal contact, and the friction coefficient was stable from the beginning. Fluctuation in the coefficient of friction was much less and reached a value of 0.6 in a very short time. This is more evidence of the wear mechanism being other than adhesive [35].

In Figures 10 and 11, it is clear that the two groups of specimens presented different wear mechanisms. This is additionally seen in Figure 8. Thus, for the untreated alloy, the friction process typically begins from the reconfiguration of the as-ground surface. Due to plastic deformation, the asperities change their shape and the number of contact points increases [64]. The COF oscillations and morphology peculiarities, seen especially in Figure 10b, indicate the sticking of contacting surfaces. Furthermore, these deformed asperities and the sides of the wear grooves are deformed into thin foils (Figure 10c), which tear off and become wear products. After being processed multiple times by the counterpart, these secondary wear products may adhere back to the surface and subsequently fracture into much smaller particles (Figure 10d) or may roll into large wear particles (Figure 10e) and cause severe damage to the surface (Figure 10a). A detailed analysis of the wear particles (Figure 10e) indicates the possibility of agglomeration when several torn-off particles roll into one. Therefore, for this tribocouple, we may conclude that the wear mechanism was predominantly adhesion-delamination.

For nitrided specimens, the wear mechanism was different. Nitrogen in the surface reduced the capacity for adhesive wear, despite the counterpart being fabricated of untreated BT22 titanium alloy, as in the previous case [63]. Therefore, less evidence of adhesive wear was seen. The harder and more brittle modified layer produced wear particles of submicrometer size. As may be seen in Figure 11b,d, they can be assumed to have formed as a result of the destruction of the "horns" formed during friction. They continued to damage the surface (Figure 11e), producing fine wear grooves (Figure 11e). The nature of the "horns" is questionable. They may result from the adhesion [63] or destruction of the leading edge of the metal outflows (Figure 11c), through oxidation or by fatigue wear mechanisms. Considering the nature of the friction coefficient diagrams (Figure 8), the adhesion is a supplementary wear mechanism, while fatigue and abrasion are dominant. The possibility of adhesion and abrasion wear in titanium alloys has been proven in [65]. Importantly, due to small amounts of TiN being formed, three-body abrasive phenomena were not detected.

The wear loss of the nitrided alloy was half that of the untreated alloy. Nitriding in specially designed conditions decreases the wear loss by a magnitude of 3-5 [35], or even 7 [34]. In our case, an increase in wear resistance and surface hardness were benefits obtained by combining heat treatment and thermochemical processing. No additional time, energy or equipment was used. Taking this into account, the result begs to be noticed. As mentioned, we used the untreated BT22 titanium alloy as a counterpart, which may have contributed to the increased wear by adhering to and deteriorating the nitrided layer.

This surface strengthening method was studied only for the duplex aging process at $750-850{ }^{\circ} \mathrm{C}$. However, BT22 alloys may be used in various conditions (quenching, annealing, annealing/quenching and aging) [11,12], and the highest strength ( $\sigma_{\mathfrak{u}}$ up to $1400 \mathrm{MPa}$, [11]) can be achieved after quenching and aging at $480-650{ }^{\circ} \mathrm{C}$, which is not enough for nitriding. It has to be stressed that while the wear resistance of the alloy can be improved due to nitriding, some of the mechanical properties of the alloy will have to be sacrificed. The alpha case formed during the proposed thermochemical treatment is suitable for the limited 
industrial application of titanium alloys. Therefore, it is necessary to find the combination of process parameters to minimize the impact on the performance of the parts, to reduce the thickness of the compound layer and to expand the nitrogen diffusion zone [66].

\section{Conclusions}

The studied duplex method of gas nitriding during the regular heat treatment of a BT22 titanium alloy increased the surface microhardness from 300 to $715 \mathrm{HV}_{0.01}$. The maximum microhardness value of $1190 \mathrm{HV}_{0.01}$ was achieved on the top surface of the sample. According to XRD studies, a multiphase layer consisting of $\mathrm{Ti}_{2} \mathrm{~N}, \mathrm{TiN}, \mathrm{Ti}_{2} \mathrm{O}$ and the metal phase was formed. The proposed thermochemical process improved the wear resistance of the BT22 alloy two-fold. Nitriding reduced the adhesion interactions between the sample and the counterparts. The wear mechanism of the untreated alloy in the pin-on-disc configuration was adhesion-delamination wear. For the nitrided alloy, the dominant wear process was fatigue wear, accompanied by adhesion. The tree-body abrasion phenomenon on the friction surface was not observed. This method (duplex treatment: nitriding during aging) reduced the steps in the process and the manufacturing costs of wear-tolerant titanium alloys. The method also achieved twice the wear resistance with no additional time and energy consumption.

Author Contributions: Conceptualization, O.T.; methodology, M.Ł., O.T. and Y.T.; validation, O.T. and M.Ł.; formal analysis, M.K. and O.D.; investigation, O.T., M.Ł. and Y.T.; writing-original draft preparation, O.T. and A.Y.; writing—review and editing, M.Ł. and O.T.; visualization, O.T. and A.Y.; supervision, M.Ł. All authors have read and agreed to the published version of the manuscript.

Funding: This research was funded by the Ministry of Education and Science of Ukraine (project number 0120U101988). This manuscript's open access publishing was funded by the Ministry of Science and Higher Education in Poland, Regional Initiative of Excellence Program in 2019-2022, project No. 011/RID/2018/19.

Data Availability Statement: The data that support the findings of this study are available from the corresponding author upon reasonable request.

Acknowledgments: The authors express gratitude to Iryna Pohreliuk (Karpenko Physico-Mechanical Institute of the NAS of Ukraine), who prepared the specimens and made this study possible.

Conflicts of Interest: The authors declare that they have no known competing financial interests or personal relationships that could have appeared to influence the work reported in this study.

\section{References}

1. Li, C.; Li, H.; van der Zwaag, S. Unravelling the abrasion resistance of two novel meta-stable titanium alloys on the basis of multi-pass-dual-indenter tests. Wear 2019, 440-441, 203094. [CrossRef]

2. Sandomierski, M.; Buchwald, T.; Patalas, A.; Voelkel, A. Improving the abrasion resistance of Ti6Al4V alloy by modifying its surface with a diazonium salt and attaching of polyurethane. Sci. Rep. 2020, 10, 19289. [CrossRef]

3. Dong, H. Tribological properties of titanium-based alloys. In Woodhead Publishing Series in Metals and Surface Engineering, Surface Engineering of Light Alloys; Woodhead Publishing: Cambridge, UK, 2010; pp. 58-80. [CrossRef]

4. Grigoriev, O.N.; Mazur, P.V.; Neshpor, I.P.; Mosina, T.V.; Bega, M.D.; Varchenko, V.T.; Vedel, D.V.; Konoval, V.P.; Dukhota, A.I.; Kharchenko, V.V.; et al. Wear-Resistant TiCN-Based Ceramic Materials for High-Load Friction Units. Powder Metall. Met. Ceram. 2021, 59, 528-536. [CrossRef]

5. Yang, Q.; Zhou, W.; Zheng, X.; Niu, Z.; Li, Z.; Zou, B.; Fu, X. Investigation of shot peening combined with plasma-sprayed CuNiIn coating on the fretting fatigue behavior of Ti-6Al-4V dovetail joint specimens. Surf. Coat. Technol. 2019, 358, 833-842. [CrossRef]

6. AMS4911R. Titanium Alloy, Sheet, Strip, and Plate 6Al—4V Annealed; SAE International: Warrendale, PA, USA, 2019.

7. AMSH81200D. Heat Treatment of Titanium and Titanium Alloys; SAE International: Warrendale, PA, USA, 2014.

8. AMS2801B. Heat Treatment of Titanium Alloy Parts; SAE International: Warrendale, PA, USA, 2014.

9. AMS2488E. Anodic Treatment-Titanium and Titanium Alloys Solution pH 13 or Higher; SAE International: Warrendale, PA, USA, 2019.

10. AMS2487B. Anodic Treatment of Titanium and Titanium Alloys Solution pH 12.4 Maximum; SAE International: Warrendale, PA, USA, 2018.

11. Anoshkin, N.F. Titanium Alloys. Metallography of Titanium Alloys; Metallurgy: Moscow, USSR, 1980; 464p.

12. Khorev, A.I. Alloying and Heat treatment of high-strength structural titanium $\beta$ alloys. Russ. Eng. Res. 2010, 30, 781-788. [CrossRef] 
13. Weiss, I.; Semiatin, S.L. Thermomechanical processing of beta titanium alloys-An overview. Mater. Sci. Eng. A 1998, $243,46-65$. [CrossRef]

14. Shekhar, S.; Sarkar, R.; Kar, S.K.; Bhattacharjee, A. Effect of Solid solution treatment and aging on microstructure and tensile properties of high strength $\beta$ titanium alloy, Ti-5Al-5V-5Mo-3Cr. Mater. Des. 2015, 66, 596-610. [CrossRef]

15. Glazunov, S.; Moiseev, V. Titanium Alloys. Structural Titanium Alloys; Metallurgy: Moscow, USSR, 1974; 368p.

16. Yan, D.P.; Hilditch, T.; Kishawy, H.A.; Littlefair, G. On Quantifying the Strain Rate During Chip Formation When Machining Aerospace Alloy Ti-5553. Procedia CIRP 2013, 8, 123-128. [CrossRef]

17. Parida, A.K.; Maity, K. Analysis of some critical aspects in hot machining of Ti-5553 superalloy: Experimental and FE analysis Def. Technol. 2019, 15, 344-352. [CrossRef]

18. Wagner, V.; Baili, M.; Dessein, G. The relationship between the cutting speed, tool wear, and chip formation during Ti-5553 dry cutting. Int. J. Adv. Manuf. Technol. 2015, 76, 893-912. [CrossRef]

19. Opini, V.C.; Salvador, C.A.F.; Campo, K.N.; Lopes, E.S.N.; Chaves, R.R.; Caram, R. $\alpha$ phase precipitation and mechanical properties of Nb-modified Ti-5553 alloy. Mater. Sci. Eng. A 2016, 670, 112-121. [CrossRef]

20. Ghosh, A.; Sivaprasad, S.; Bhattacharjee, A.; Kar, S.K. Microstructure-fracture toughness correlation in an aircraft structural component alloy Ti-5Al-5V-5Mo-3Cr. Mater. Sci. Eng. A 2013, 568, 61-67. [CrossRef]

21. Huang, C.; Zhao, Y.; Xin, S.; Zhou, W.; Li, Q.; Zeng, W. Effect of microstructure on tensile properties of Ti-5Al-5Mo-5V-3Cr-1Zr alloy. J. Alloys Compd. 2017, 693, 582-591. [CrossRef]

22. Li, P.; Sun, Q.; Xiao, L.; Sun, J. Tuning the morphology of Ti-5Al-5Mo-5V-3Cr-1Zr alloy: From brittle to ductile fracture. Mater. Sci. Eng. A 2020, 769, 138487. [CrossRef]

23. Qin, D.; Lu, Y.; Guo, D.; Zheng, L.; Liu, Q.; Zhou, L. Tensile deformation and fracture of Ti-5Al-5V-5Mo-3Cr-1.5Zr-0.5Fe alloy at room temperature. Mater. Sci. Eng. A 2013, 587, 100-109. [CrossRef]

24. Wu, C.; Zhao, Y.; Huang, S.; Lei, L.; Zhao, Q.; Sun, Q.; Zhou, L. Microstructure tailoring and impact toughness of a newly developed high strength Ti-5Al-3Mo-3V-2Cr-2Zr-1Nb-1Fe alloy. Mater. Charact. 2021, 175, 111103. [CrossRef]

25. Wang, H.; Xin, S.W.; Zhao, Y.Q.; Zhou, W.; Zeng, W.-D. Forging-microstructure-tensile properties correlation in a new near $\beta$ high-strength titanium alloy. Rare Met. 2020, 40, 2109-2117. [CrossRef]

26. Wang, Z.-Y.; Liu, L.-B.; Wu, D.; Zhang, L.-G.; Wang, W.-L.; Zhou, K.-C. $\alpha$ " phase-assisted nucleation to obtain ultrafine $\alpha$ precipitates for designing high-strength near- $\beta$ titanium alloys. Trans. Nonferrous Met. Soc. China 2020, 30, 2681-2696. [CrossRef]

27. Ivasishin, O.M.; Markovsky, P.E.; Semiatin, S.L.; Ward, C.H. Aging response of coarse- and fine-grained $\beta$ titanium alloys. Mater Sci. Eng. A 2005, 405, 296-305. [CrossRef]

28. Zherebtsov, S.V.; Murzinova, M.A.; Klimova, M.V.; Salishchev, G.A.; Popov, A.A.; Semiatin, S.L. Microstructure evolution during warm working of Ti-5Al-5Mo-5V-1Cr-1Fe at 600 and $800{ }^{\circ} \mathrm{C}$. Mater. Sci. Eng. A 2013, 563, 168-176. [CrossRef]

29. Zhang, H.; Shao, H.; Shan, D.; Wang, K.; Cai, L.; Yin, E.; Wang, Y.; Zhuo, L. Influence of strain rates on high temperature deformation behaviors and mechanisms of Ti-5Al-5Mo-5V-3Cr-1Zr alloy. Mater. Charact. 2021, 171, 110794. [CrossRef]

30. Łępicka, M.; Grądzka-Dahlke, M.; Pieniak, D.; Pasierbiewicz, K.; Kryńska, K.; Niewczas, A. Tribological performance of titanium nitride coatings: A comparative study on TiN-coated stainless steel and titanium alloy. Wear 2019, 422-423, 68-80. [CrossRef]

31. Łępicka, M.; Gradzka-Dahlke, M. Surface modification of Ti6Al4V titanium alloy for biomedical applications and its effect on tribological performance-A review. Rev. Adv. Mater. Sci. 2016, 46, 86-103.

32. Fedirko, V.M.; Pohrelyuk, I.M.; Luk'yanenko, O.H.; Lavrys', S.M.; Kindrachuk, M.V.; Dukhota, O.I.; Tisov, O.V.; Zahrebel'nyi, V.V. Thermodiffusion saturation of the surface of VT22 titanium alloy from a controlled oxygen-nitrogen-containing atmosphere in the stage of aging. Mater. Sci. 2018, 53, 691-701. [CrossRef]

33. Pohrelyuk, I.M.; Kindrachuk, M.V.; Lavrys', S.M. Wear resistance of VT22 titanium alloy after nitriding combined with heat treatment. Mater. Sci. 2016, 52, 56-61. [CrossRef]

34. Szymkiewicz, K.; Morgiel, J.; Maj, Ł.; Pomorska, M.; Tarnowski, M.; Tkachuk, O.; Wierzchoń, T. Effect of nitriding conditions of Ti6Al7Nb on microstructure of TiN surface layer. J. Alloys Compd. 2020, 845, 156320. [CrossRef]

35. Taktak, S.; Akbulut, H. Dry wear and friction behaviour of plasma nitrided Ti-6AL-4V alloy after explosive shock treatment. Tribol. Int. 2020, 40, 423-432. [CrossRef]

36. El-Hossary, F.M.; Negm, N.Z.; Abd El-Rahman, A.M.; Raaif, M.; Seleem, A.A.; Abd El-Moula, A.A. Tribo-mechanical and electrochemical properties of plasma nitriding titanium. Surf. Coat. Technol. 2015, 276, 658-667. [CrossRef]

37. Borisyuk, Y.V.; Oreshnikova, N.M.; Berdnikova, M.A.; Tumarkin, A.V.; Khodachenko, G.V.; Pisarev, A.A. Plasma nitriding of titanium alloy Ti5Al4V2Mo. Phys. Procedia 2015, 71, 105-109. [CrossRef]

38. Shen, H.; Wang, L. Formation, tribological and corrosion properties of thicker Ti-N layer produced by plasma nitriding of titanium in a $\mathrm{N}_{2}-\mathrm{NH}_{3}$ mixture gas. Surf. Coat. Technol. 2020, 393, 125846. [CrossRef]

39. She, D.; Yue, W.; Fu, Z.; Wang, C.; Yang, X.; Liu, J. Effects of nitriding temperature on microstructures and vacuum tribological properties of plasma-nitrided titanium. Surf. Coat. Technol. 2015, 264, 32-40. [CrossRef]

40. Shen, H.; Wang, L. Corrosion resistance and electrical conductivity of plasma nitrided titanium. Int. J. Hydrogen Energy 2021, 46, 11084-11091. [CrossRef]

41. Escalona, M.; Bhuyan, H.; Ibacache, S.; Retamal, M.J.; Saikia, P.; Borgohain, C.; Valenzuela, J.C.; Veloso, F.; Favre, M.; Wyndham, E. Study of titanium nitride film growth by plasma enhanced pulsed laser deposition at different experimental conditions. Surf. Coat. Technol. 2021, 405, 126492. [CrossRef] 
42. Abboud, J.H. Effect of processing parameters on titanium nitrided surface layers produced by laser gas nitriding. Surf. Coat. Technol. 2013, 214, 19-29. [CrossRef]

43. Marchuk, V.; Kindrachuk, M.; Tisov, O.; Kornienko, A.; Radko, O.; Kharchenko, V. Stress-strained state of textured surfaces with selectively indented regions. Funct. Mater. 2019, 26, 773-778. [CrossRef]

44. Kindrachuk, M.; Shevchenko, A.; Kryzhanovskyi, A. Improvement of the quality of TiC-Co system plasma coating by laser treatment. Aviation 2016, 20, 155-159. [CrossRef]

45. Katahira, K.; Tanida, Y.; Takesue, S.; Komotori, J. Rapid surface nitriding of titanium alloy by a nanosecond fiber laser under atmospheric conditions. CIRP Ann. 2018, 67, 563-566. [CrossRef]

46. Senthilselvan, J.; Monisha, K.; Gunaseelan, M.; Yamini, S.; Arun Kumar, S.; Kanimozhi, K.; Manonmani, J.; Shariff, S.M.; Padmanabham, G. High power diode laser nitriding of titanium in nitrogen gas filled simple acrylic box container: Microstructure, phase formation, hardness, dendrite and martensite solidification analyses. Mater. Charact. 2020, 160, 110118. [CrossRef]

47. Takesue, S.; Kikuchi, S.; Akebono, H.; Morita, T.; Komotori, J. Characterization of surface layer formed by gas blow induction heating nitriding at different temperatures and its effect on the fatigue properties of titanium alloy. Results Mater. 2020, 5, 100071. [CrossRef]

48. Takesue, S.; Kikuchi, S.; Akebono, H.; Misaka, Y.; Komotori, J. Effect of pre-treatment with fine particle peening on surface properties and wear resistance of gas blow induction heating nitrided titanium alloy. Surf. Coat. Technol. 2019, 359, 476-484. [CrossRef]

49. Takesue, S.; Kikuchi, S.; Misaka, Y.; Morita, T.; Komotori, J. Rapid nitriding mechanism of titanium alloy by gas blow induction heating. Surf. Coat. Technol. 2020, 399, 126160. [CrossRef]

50. Takesue, S.; Kikuchi, S.; Akebono, H.; Komotori, J.; Fukazawa, K.; Misaka, Y. Effects of gas blow velocity on the surface properties of Ti-6Al-4V alloy treated by gas blow IH nitriding. Mater. Trans. 2017, 58, 1155-1160. [CrossRef]

51. Burdovitsin, V.A.; Golosov, D.A.; Oks, E.M.; Tyunkov, A.V.; Yushkov, Y.G.; Zolotukhin, D.B.; Zavadsky, S.M. Electron beam nitriding of titanium in medium vacuum. Surf. Coat. Technol. 2019, 358, 726-731. [CrossRef]

52. Tyunkov, A.V.; Golosov, D.A.; Zolotukhin, D.B.; Nikonenko, A.V.; Oks, E.M.; Yushkov, Y.G.; Yakovlev, E.V. Nitriding of titanium in electron beam excited plasma in medium vacuum. Surf. Coat. Technol. 2020, 383, 125241. [CrossRef]

53. Liang, S.X.; Yin, L.X.; Liu, X.Y.; Wu, X.X.; Ma, M.Z.; Liu, R.P. Kinetics of thermodiffusion of TZ20 titanium alloy gas-nitride within temperature of $500{ }^{\circ} \mathrm{C}-650{ }^{\circ} \mathrm{C}$. J. Alloys Compd. 2018, 734, 172-178. [CrossRef]

54. Yang, C.; Liu, J. Intermittent vacuum gas nitriding of TB8 titanium alloy. Vacuum 2019, 163, 52-58. [CrossRef]

55. Zhecheva, A.; Malinov, S.; Sha, W. Titanium alloys after surface gas nitriding. Surf. Coat. Technol. 2006, 201, 2467-2474. [CrossRef]

56. Toboła, D.; Morgiel, J.; Maj, Ł. TEM analysis of surface layer of Ti-6Al-4V ELI alloy after slide burnishing and low-temperature gas nitriding. Appl. Surf. Sci. 2020, 515, 145942. [CrossRef]

57. Jeong, H.-G.; Lee, Y.; Lee, D.-G. Effects of preheat conditions on diffusion hardening of pure titanium by vacuum rapid nitriding Surf. Coat. Technol. 2017, 326, 395-401. [CrossRef]

58. Ajikumar, P.K.; Kamruddin, M.; Shankar, P.; Gouda, R.; Balamurugan, A.K.; Nithya, R.; Raj, B. Internal nitride formation during gas-phase thermal nitridation of titanium. Scr. Mater. 2009, 61, 403-406. [CrossRef]

59. Łępicka, M.; Gradzka-Dahlke, M. The initial evaluation of performance of hard anti-wear coatings deposited on metallic substrates: Thickness, mechanical properties and adhesion measurements-A brief review. Rev. Adv. Mater. 2019, 58, 50-65. [CrossRef]

60. Dong, H. Surface Engineering of Light Alloys. Aluminium, Magnesium and Titanium Alloys, 1st ed.; Woodhead Publishing: Cambridge, UK, 2010; 680p.

61. Dong, H.; Bell, T. Enhanced wear resistance of titanium surfaces by a new thermal oxidation treatment. Wear 2000, 238, 131-137. [CrossRef]

62. Cherepova, T.; Dmitrieva, G.; Tisov, O.; Dukhota, O.; Kindrachuk, M. Research on the properties of Co-TiC and Ni-TiC HIPsintered alloys. Acta Mech. Autom. 2019, 13, 57-67. [CrossRef]

63. Pohrelyuk, I.M.; Padgurskas, J.; Lavrys, S.M.; Luk'yanenko, A.G.; Trush, V.S.; Kreivaitis, R. Topography, hardness, elastic modulus and wear resistance of nitride coatings on titanium. In Proceedings of the 9th International Conference BALTTRIB' 2017, Kaunas, Lithuania, 16-17 November 2017. [CrossRef]

64. Çelik, A.; Acar, M.T.; Yetim, T.; Kovac1, H.; Yetim, A.F. Improving structural, tribological and electrochemical properties of Ti6Al4V alloy with B-doped $\mathrm{TiO}_{2}$ thin films. Tribol. Int. 2020, 146, 106210. [CrossRef]

65. Alam, M.O.; Haseeb, A.S.M.A. Response of Ti-6Al-4V and Ti-24Al-11Nb alloys to dry sliding wear against hardened steel. Tribol. Int. 2002, 35, 357-362. [CrossRef]

66. Qian, J. Ion Nitriding of Ti-10V-2Fe-3Al Alloy for Aerospace Applications. Master's Thesis, University of Windsor, Ottawa, CA, USA, 2013; 254p. 